\title{
AUGUSTO ÓPẼ DA SILVA: CAMINHO ETERNO NA LUTA DOS POVOS INDÍGENAS
}

MATIAS BENNO REMPEL ${ }^{1}$

UFSM

Era hora avançada, quase duas da madrugada. Com muita expectativa, eu esperava na estação rodoviária de Santa Maria, pequena cidade do interior do Rio Grande do Sul, por um ônibus que vinha das bandas do norte do Estado. Isso foi há quatro anos atrás.

Eu me encontrava ansioso, lembro bem, porque naquele ônibus, que vinha da cidade de Iraí direto ao meu encontro, viajava uma pessoa referendada pelos povos indígenas como uma grande liderança. Tratava-se de alguém com peso histórico. O grande Augusto Ópẽ da Silva, todos diziam. Na época, se iniciava, na Universidade Federal de Santa Maria (UFSM), uma discussão mais acentuada sobre o ingresso de acadêmicos indígenas, já que na instituição havia sido implementada dois anos antes a política de cotas. Porém, a universidade, vestida de sua inércia e desinteresse por popularizar-se e receber dentro de seus muros o povo, fazia pouco caso em pintar-se de originária e criar pela própria vontade seu corpo docente e administrativo um programa que atendesse as expectativas dos povos indígenas.

Por admiração despertada pela movimentação e resistência dos próprios povos indígenas, que já há tempos lutavam por seus territórios e políticas básicas nos arredores de nossa cidade, havíamos fundado recentemente e entre algumas poucas pessoas o Grupo de Apoio aos Povos Indígenas (GAPIN). Como única referência indigenista de uma pequena cidade, nossa organização foi indicada pelo Diretório Central

\footnotetext{
${ }^{1}$ Acadêmico do curso de História na Universidade Federal de Santa Maria. Atua no Conselho Indigenista Missionário (Cimi) em Mato Grosso do Sul. E-mail: matias.b.rempel@gmail.com .
}

Espaço Ameríndio, Porto Alegre, v. 8, n. 2, p. 376-385, jul./dez. 2014. 
dos Estudantes da UFSM, do qual na época eu fazia parte, para acompanhar a implementação da política de cotas na universidade.

O próprio desconhecimento, tanto nosso como da Universidade, em lidar com os povos indígenas e as culturas originárias no que se referia às questões ligadas à educação acabou por abrir espaço para a participação direta dos povos indígenas na construção da política afirmativa. Era a chance para que os povos indígenas assumissem as rédeas do processo histórico de construção de uma política educacional que Ihes pertencesse.

Por indicação de um servidor da universidade chamado José Maximo Ilha Noya e por indicação unânime também dos indígenas kaingang e guarani que até então conhecíamos, liguei para Augusto. Do outro lado do telefone, com voz calma, depois de ouvir o que eu relatava, perguntou-me apenas quando precisaria estar em Santa Maria. De prontidão aceitou viajar mesmo no dia seguinte. Quando expliquei a Augusto que não havia diárias e demais recursos, o mesmo, sem apresentar ressalvas, apenas pediu que eu o recebesse na rodoviária.

Lembro com carinho dele chegando. Passos curtos mas decididos, avistei seus traços indígenas de longe. Admito que o grande líder indígena me pareceu um tanto frágil num primeiro olhar. Carregava uma grande mala cheia de ferrolhos pesados de uma estrutura que trazia para expor e vender seu artesanato. Depois entendi que muitas vezes a venda deste artesanato era a única forma que tinha de juntar algum recurso para que em sua volta pudesse ajudar sua família. Estava visivelmente cansado. Na verdade parecia exausto, como se já estivesse caminhando há muitos dias sem parar, o que de fato ele vinha fazendo.

Porém, não foi preciso mais do que alguns minutos para que aquela fragilidade aparente desaparecesse, me fazendo descobrir que acima de sua pouca estatura se estendia uma envergadura de mais de 500 anos de resistência que se manifestava na forma de um brado ancestral cada vez que Augusto falava em defesa de seu povo.

Ao me olhar, Augusto, de maneira gentil, me chamou pelo nome, estendeu-me a mão e me desejou boa noite. Retribui os cumprimentos e pedi a ele que fossemos, pois a hora se desenrolava rápida pela noite, e o compromisso que tínhamos com a universidade aconteceria logo cedo pela manhã. 
O pedido para irmos pareceu não ter chegado ao conhecimento de Augusto, que, para minha surpresa, perguntou com timbre forte: "Fiquei sabendo que meu povo segue acampado por aqui, perto dessa rodoviária e que não esta em boas condições, você sabe onde estão?". Confirmei para Augusto que sim, que sabia onde estavam. Na verdade, fazia poucos dias que havia tido o primeiro contato com estes indígenas kaingang dos quais Augusto se referia. Sugeri a Augusto que fôssemos para minha casa, que descansássemos e que após a reunião com a universidade eu lhe traria até o acampamento. Lembro que Augusto sorriu meio contrariado, provavelmente incomodado com o que deve ter interpretado como minha falta de solidariedade para com seu povo, e disse: "minha prioridade é o povo Kaingang, se eles estão aqui, e não estão bem, quero vê-los agora, depois descansamos".

Vi logo que não haveria qualquer chance de negociação, marca registrada de Augusto quando se tratava da defesa dos direitos e da defesa dos povos indígenas. Atitude que tive a oportunidade de acompanhar em diversas vezes quando ele esteve frente a frente com representantes do governo ou até mesmo dos setores dominantes. Pedi então que me alcançasse a mala, pesava muito. Indiquei o caminho e pusemo-nos a caminhar lado a lado até chegarmos ao acampamento improvisado dos indígenas.

Ao chegarmos, Augusto olhou, parou, olhou de novo. Balançou a cabeça negativamente, comovido com a situação vivida por seu povo. Sentiu com a mão a fragilidade das "ocas de lona preta" e com o coração sentiu a miserabilidade que se fazia vizinha de cada um dos barracos. Com autoridade, mas com muito respeito adentrou o lugar. $O$ único rapaz que se mantinha acordado, sentado ao lado de uma pequena fogueira, ao reconhecer o semblante de Augusto, que pouco a pouco foi tomando forma contra a luz do fogo, exclamou algo que não compreendi em kaingang, estendeu a mão e então disse seu nome vagarosamente, sorrindo muito. Fiquei atônito. O primeiro indígena a ver Augusto, não aparentando ser nem mesmo uma liderança, mas sim mais um dos tantos indígenas moradores do local, o conheceu tão prontamente. O homem alegrou-se tanto com sua presença que me deixou pensando por alguns segundos se todos os Kaingang do Estado conheciam Augusto. 
Sentaram-se os dois, aos poucos mais indígenas acordaram com o som animado da conversa, animaram-se como embalados pelas palavras e foram fechando uma roda ao redor da fogueirinha. Augusto perguntou quem era o cacique. Quando the foi indicado, Augusto o cumprimentou respeitosamente e pediu-Ihe permissão para falar. Eram passadas das três horas da manhã quando iniciada a primeira assembleia da Ketyjug Tegtu, carinhosamente conhecida hoje entre os Kaingang como "aldeia da rodoviária". Após aquele dia, a luta pelo território kaingang tomou cores e formas mais fortes na cidade. Naquela noite, a história secular deste povo em Santa Maria pareceu tomar consciência de que afloraria no despertar coletivo dos Kaingang. Casas reforçadas foram construídas pela primeira vez em um território ocupado por barracas há mais de 15 anos. Hoje a aldeia possui escola, agente de saúde, tem plantação, tem vida. Nela as crianças falam a língua e cultivam sua tradição. Os pequenos indígenas, conscientes do que são, trazem e levam junto a si o significado do que Augusto chamava de "esperança pelo amanhã". O povo, naquela histórica noite, despertou de seu sono profundo, empoderou-se da consciência de seus direitos constitucionais e originários. A capacidade de resistência daquelas pessoas encontrou as palavras que lhes proporcionou coragem e convicção. Augusto, ao recordar deste fato mais tarde, quando, numa roda de chimarrão, eu lhe fiz menção, apenas disse: "Tudo o que eles precisavam já estava lá, dentro do peito de cada um e cada uma, só precisavam se conhecer enquanto povo".

Lembro que, naquela noite, dormimos, se muito, duas horas antes de partirmos para a reunião que abriria definitivamente as portas da UFSM para os povos indígenas...

...Quatro anos mais tarde, em uma única semana, o mundo indígena "perdeu" dois de seus maiores mestres. Na madrugada do dia 25 de Maio de 2014, Marcos, o simbólico e lendário subcomandante indígena zapatista, anunciou ao mundo que deixava de existir. Foi um enterro didático frente a uma realidade onde lideranças dos mais diversos povos e países, distanciadas das bases, passavam a se portar cada vez mais como figurões representativos. Na ocasião, Marcos anunciou ao mundo que se despedia para dar lugar a um novo líder. Mas que este novo líder, assim como ele, não era uma pessoa. Em 
tempos de crises na esquerda, assumiu novamente a frente do movimento zapatista, o povo e sua união em torno do poder popular. Foram estas as últimas palavras do subcomandante:

\begin{abstract}
É nossa convicção e nossa prática, que para levantar e lutar não são necessários líderes nem caudilhos, nem messias nem salvadores. Para lutar só é preciso um pouco de vergonha, um tanto de dignidade e muita organização, o demais serve ao coletivo ou não serve.
\end{abstract}

Seis dias depois, dia 31 de Maio, ao atender telefonema de Sandro da Silva, filho de Augusto, e ouvir de imediato suas palavras pronunciadas com dificuldades em meio ao choro, tomei consciência de que o querido mestre kaingang havia deixado este mundo. Augusto vinha enfrentando uma forte doença sanguínea que agravou-se com o acúmulo dos anos desregrados e pouco confortáveis de luta e de estrada. Augusto comia quando dava, enfrentava sol e chuva para poder caminhar junto com seu povo, quase não via a família, não reclamava. Só parou quando as dores decorrentes da doença, em estágio muito avançado, foram tão fortes que praticamente o impossibilitaram de caminhar. Mesmo hospitalizado acompanhava atento os desdobramentos da luta pelos territórios indígenas, que se intensificava no estado. Por duas vezes deixou o hospital para, com voz forte e segura, lembrar o Estado e o Governo de suas responsabilidades para com os povos originários.

Dizer que Augusto foi liderança fundamental para muitos entre os povos indígenas não é em nada contraditório aos ditos zapatistas. Pelo contrário. Augusto em vida foi a personificação do que pregara Marcos na despedida do subcomandante. Sempre se referiu às lideranças, inclusive a ele mesmo, como uma simples extensão do povo. "A verdadeira força está nas bases, só a força coletiva pode conquistar os direitos de nosso povo", dizia ele em meio a seus sábios conselhos. Mesmo nunca se furtando dos grandes fóruns de debates contra o Estado, Augusto nunca foi um "lutador de holofotes". Era reconhecido pelos povos porque estava sempre em meio deles. Não só dos caciques, mas entre os jovens e os homens e mulheres "comuns". Costurava mosaicos de união e fortalecimento entre as aldeias, foi sempre mais caminhos que morada. De aldeia em aldeia, estrada em estrada, 
convidava o povo a não esmorecer na luta justa pela tradicionalidade de seus territórios. Estendeu sua solidariedade e conhecimento para além do povo Kaingang. Atuou junto à luta de dezenas de povos indígenas, em especial junto aos Guarani, Xokleng e Xetá. O empoderamento das bases, a coletividade e a articulação entre os povos indígenas eram para ele princípios sagrados.

Conhecedor dos males do capitalismo, Augusto falava em "globalização social das lutas, contra a globalização do sistema de opressão" e assim semeava a consciência de que a luta dos pobres e dos grupos marginalizados era também a luta dos povos indígenas. Que era preciso que estes segmentos se unificassem baseado no respeito às diferenças para atingir um mundo melhor.

Lembro bem de uma vez, em um quarto de hospital em Santa Maria, em que, na televisão, certo secretário de governo falava demagogicamente em pagar para os agricultores saírem das terras reivindicadas pelos indígenas, possibilitando assim as demarcações. Qualquer liderança indígena deveria ter ficado feliz com a possibilidade de reaver suas terras, mas Augusto franziu a testa e exclamou: "Isto é um absurdo". Olhei pensativo para ele sem dizer nada e ele calmamente prosseguiu:

Os agricultores não devem deixar de serem agricultores, eles têm, assim como nós, sua cultura diferenciada, a cultura do campo. Não queremos que o Governo pague para que vão embora e deixem de ser o que são. Eles devem ser reassentados, poder viver como sabem, terem o seu direito assim como nós temos. Nós, os pequenos, não podemos ser exterminados para manter a paz dos grandes proprietários.

Augusto morreu semeando em palavras o que para ele seria uma grande articulação entre o campo, a cidade e a "floresta".

Do ponto de vista pessoal, Augusto era alguém que possuía os olhos úmidos e cheios de brilho e esperança. Quem teve oportunidade de vê-lo em Iraí, em sua aldeia, rodeado por sua família certamente entendeu o significado do que dizia Che quando falava em "endurecer sem perder a ternura jamais". O homem de postura inegociável em frente ao governo, em casa virava em risos altos, brincadeiras, 
companheirismo e carinho, muito carinho. Para Augusto, não havia lugar melhor que o pé do fogo que ficava dentro do "puxadinho", como ele se referia, em um galpãozinho anexo à sua morada. Lá, junto a sua esposa Lurdes, seus filhos e seus netos, compartilhava a vida no que considerava os seus melhores momentos. Não por poucas vezes vi Augusto chorar após, por telefone, escutar os netos pedindo para que ele voltasse para casa. A negação destes momentos para fazer da estrada sua morada e ao longo delas semear esperança demonstram o tamanho do sacrifício que Augusto fez por seu povo.

Em seu enterro, lideranças de muitos cantos e aldeias do estado e para além dele se fizeram presentes e lembraram com tristeza, porém com esperança, de seus ensinamentos e de sua importância. Em um rito de passagem cheio de tradicionalidade e mística, reafirmaram a necessidade de seguir o caminho deixado por Augusto, e mesmo sendo o sentimento geral de orfandade, proclamaram que Ópẽ viverá para sempre nos feitos futuros do povo, e que sua sabedoria segue com cada um dos que ficaram. Para os Kaingang, Augusto não morreu, ele apenas foi plantado de novo junto à terra.

O legado de Augusto para as futuras gerações, sempre junto às conquistas coletivas do povo, é incalculável. Esteve presente e foi peça chave nas grandes campanhas de demarcação de terras indígenas da década de 90, que resultou em uma série de (re)conquistas fundamentais de áreas tradicionalmente ocupadas pelos indígenas. Contra as pretensões dos governos, Augusto sempre foi voz forte na defesa da tradicionalidade, lembrando que a terra não pode ser comprada ou vendida, pois é um bem sagrado que pertence ao povo. Tinha na luta geral das bases e na pressão popular convicção inabalável e, de maneira incansável, fez destas bandeiras as ferramentas para atingir a conquista dos direitos dos povos indígenas. Creio que, em memória coletiva, Augusto Ópẽ da Silva será lembrado como aquele para o qual os direitos de seu povo eram inegociáveis.

Também em sua trajetória foi incorruptível. Mesmo sem recursos próprios, e muitas vezes ajudado por apoiadores e parceiros Augusto, negou as insistentes propostas que teve por parte dos governos de ingressar em secretarias estaduais e federais. "Eles querem me colocar rédeas que possam puxar para o lado que querem" dizia. Mesmo 
respeitando os indígenas que optassem por atuar junto às instâncias institucionais, tinha para si que sua missão era a organização de base e que a intenção governamental de maneira clara e transparente sempre foi a cooptação dos lutadores e lutadoras. Augusto contava que pelo seu caráter de sempre enfrentar as opressões do Estado sem nunca se seduzir por ele, e em decorrência dos perigos que isso trazia, um velho kujá (pajé) o batizou com o nome de "Ópẽ", que significa, na língua kaingang, gafanhoto. Desta forma ele poderia premeditar as intensões tanto dos governos quanto dos inimigos e pular para longe das armadilhas que estes preparassem. Augusto, o Ópẽ, morreu depois de décadas em que as primeiras propostas lhe foram feitas, distante do governo. Até o momento em que teve que ir às pressas para o hospital em Iraí, passou seus últimos momentos compartilhando da mesma simplicidade que o acompanhou durante a vida, ouvindo as conversas e risos de seus familiares e dividindo com eles manhãs e entardeceres ao redor de um constante fogo de chão.

Em quase todos os cantos do estado, por mais que as conquistas sejam indubitavelmente frutos coletivos da luta de incontáveis gerações, é quase impossível desbravarmos a história recente dos povos indígenas sem escutarmos ao menos menção do nome de Augusto Ópẽ da Silva. Em Santa Maria, hoje, não é diferente. A entrega de Augusto gerou tantos frutos em tantas frentes que ele se tornou uma espécie de bandeira para os indígenas da cidade. Hoje a Universidade Federal de Santa Maria possui um programa avançado de ingresso e permanência para acadêmicos indígenas. Augusto em pessoa coordenou a Comissão de Implementação e Acompanhamento do Programa Permanente de Formação de Acadêmicos Indígenas (CIAPFAI), comissão responsável pela implementação e acompanhamento do programa. Graças às concepções de Augusto, fortemente calcadas na participação direta e coletiva das bases na política e na autodeterminação dos povos indígenas, hoje a UFSM atua com um de seus pés dentro das aldeias indígenas do Rio Grande do Sul, dialogando com as comunidades indígenas sobre o ingresso e a melhora do programa em mais de 20 aldeias. Moradia estudantil, políticas de etnodireito e acompanhamento pedagógico, que ainda se encontram em estágio de aperfeiçoamento, 
também são heranças de uma luta que Augusto ajudou a construir tijolo por tijolo.

Augusto sempre lutou para que os indígenas desenvolvessem e cobrassem dos órgãos responsáveis políticas específicas que fortalecessem sua cultura e tradição, denunciando sempre as estratégias integracionistas e tuteladoras do Estado na montagem de políticas que no fundo prejudicavam os povos indígenas. Esteve presente nas movimentações que garantiram, na Carta Magna de 1988, os direitos constitucionais dos povos indígenas, porém não a referendava como algo definitivo. Definitivo para Augusto eram apenas a luta e a força do povo.

As duas Terras Indígenas, tanto a kaingang quanto a guarani, reconquistadas junto ao território do município também tiveram contribuição fundamental de Augusto. Em Ketyjug Tegtu, a escola onde estudam mais de 20 alunos indígenas foi batizada com nada mais nada menos que o seu nome, prova de carinho do povo da aldeia por Ópẽ. Augusto enfrentou de forma conjunta com o Cacique Natanael Claudino e os membros da comunidade o preconceito inicial da cidade, ações judiciais e até mesmo ameaças e atentados diretos. Se manteve firme e solidário até o momento da consolidação da aldeia. Ajudou também o povo Kaingang e Guarani a elaborarem e cobrarem dos órgãos políticas de saúde, saneamento, moradia e educação específicas para os povos indígenas, que hoje estão em curso em estágios cada vez melhores de funcionamento. Augusto sabia que seu nome desapareceria no vento, mas que suas ações morariam para sempre junto ao seu povo. O futuro do "povo do amanhã" era seu pensamento maior no presente.

Sinto que ao escrever este texto não consegui passar, nem de longe para quem o lê, a dimensão exata da grandeza deste querido amigo e pessoa. Honrosamente pude acompanhar Augusto em muitos momentos dos últimos quatro anos de sua vida. Dele me tornei admirador, depois me tornei aprendiz. Augusto reforçava em quem o conhecia a certeza de que é possível mover o mundo se a determinação e força estiverem aplicadas na direção certa, pelos motivos certos. Com ele aprendi a nunca menosprezar a força dos pequenos e que o impossível se configura apenas como uma etapa ainda não alcançada. Sua memória é um talismã que nos guiará pelos caminhos que ele 
deixou aberto para que pisássemos, para que a vida continue a poder circular.

Sinto que cada caminho que conecta hoje as aldeias do Rio Grande do Sul guarda em suas curvas e surpresas o sorriso e determinação deste amigo e lutador. Sinto que esta força pode ser sentida pelas gerações que, por estas estradas, dão seus primeiros passos. Não se preocupe, Augusto velho, o mundo kaingang continuará a caminhar. Todos agradecem seus incansáveis passos. Descanse em paz. 